\title{
El Camino de Santiago: una aproximación a su carácter polisémico desde la geografía cultural y el turismo
}

\author{
Rubén C. Lois González \\ Lucrezia Lopez \\ Universidade de Santiago de Compostela. Departamento de Xeografía \\ rubencamilo.lois@usc.es \\ lucrezia.lopez@usc.es
}

\section{Resumen}

Durante la edad media, el Camino de Santiago se consolidó como una de las tres peregrinaciones mayores, junto a Roma y a Jerusalén, y en la actualidad es sin duda la más viva. Aunque ha sufrido períodos de crisis y de abandono, desde los decenios finales del siglo xx conoce un intenso proceso de renacimiento, que se acompaña de la recuperación y actualización de la figura del peregrino. Considerando que cada período ha definido sus propios tipos de peregrinación y ha dotado al espacio sagrado de unos contenidos singulares, recorreremos brevemente los orígenes de la peregrinación jacobea, para luego detenernos en su proceso de renacimiento contemporáneo y en el peregrino turista del presente. Ponemos de manifiesto el carácter polisémico del Camino, destacando cinco factores clave que han promovido dicha renovación a lo largo del tiempo y que han contribuido a forjar la situación actual.

Palabras clave: Camino de Santiago; antropología de las peregrinaciones; espacio sagrado; geografía cultural; geografía del turismo.

Resum. El Cami de Santiago: una aproximació al seu caràcter polisèmic des de la geografia cultural $i$ del turisme

Durant l'edat mitjana, el Camí de Sant Jaume es va consolidar com una de les tres peregrinacions més conegudes, juntament amb la de Roma i Jerusalem, i en l'actualitat és, sens dubte, la més viva. Malgrat que ha sofert períodes de crisi i d'abandonament, des de les dècades finals del segle xx coneix un intens procés de renaixement, que s'acompanya de la recuperació i l'actualització de la figura del pelegrí. Considerant que cada període ha definit els seus propis tipus de peregrinació i ha dotat l'espai sagrat d'uns continguts singulars, recorrerem breument els orígens de la peregrinació jacobea, per després endinsar-nos en el procés que ha seguit de renaixement contemporani i en el pelegrí turista del present. Posem de manifest el caràcter polisèmic del Camí i en destaquem cinc factors clau que han promogut la renovació que ha protagonitzat al llarg del temps i que han contribuït a forjar la situació actual.

Paraules clau: Camí de Santiago; antropologia de les peregrinacions; espai sagrat; geografia cultural; geografia del turisme. 
Résumé. Le Chemin de Saint-Jacques : une approche à son caractère polysémique d'après la géographie culturelle et le tourisme

Pendant le Moyen Âge le Chemin de Saint-Jacques à consolidé sa position comme l'un des trois principales pèlerinages, avec Rome et Jérusalem, et actuellement est, certainement, le plus vivant. Malgré il y a eu des périodes de crise et d'abandon, depuis les dernières décennies du XXème siècle il connaît un intense processus de renaissance, qui s'accompagne de la récupération et la mise à jour de la figure du pèlerin. Tenant compte que chaque période a définie leurs pèlerinages et a doté les espaces sacrés de contenus uniques, nous parcourrons brièvement les origines du pèlerinage de Saint-Jacques et après nous tournerons l'attention vers le processus de renaissance contemporaine et le pèlerin-touriste du présent. Nous présentons le caractère polysémique du Chemin, faisant attention sur cinq facteurs clé qui ont contribué à cette mise à jour au long du temps et à son actualité.

Mots clé: Chemin de Saint-Jacques; anthropologie des pèlerinages; espace sacré; géographie culturelle; géographie du tourisme.

\section{Abstract. The Way of St. James: An Approximation to its Polysemic Character from the Viewpoint of Cultural and Tourism Geography}

During the Middle Ages, the Way of St. James was one of the three major pilgrimage routes of Christian Western Europe, together with Rome and Jerusalem. Although it has suffered times of crisis, in the last decades of the $20^{\text {th }}$ century it was largely revived and is nowadays the most vibrant pilgrimage route. This process of revival has been accompanied by the recuperation and renewal of the image of the pilgrim. Given that each period has defined its own pilgrimage patterns and endowed sacred spaces with unique characteristics, we begin by briefly exploring the origins of the Jacobean pilgrimage to then focus on the current process of revival and the contemporary pilgrim-tourist. We analyse the polysemic character of the Way by emphasising five key factors that have led to its revival over time and contributed to forging today's pilgrimage.

Keywords: Way of St. James; anthropology of pilgrimages; sacred space; cultural geography; tourism geography.

\section{Sumario}

Introducción El peregrino en la actualidad: entre legado

El Camino de Santiago: un escenario del pasado y emociones contemporáneas

para la historia Conclusiones

¿Espacio sagrado o espacio turístico? Referencias bibliográficas

Espacio polisémico

\section{Introducción}

El paso del tiempo no parece haber debilitado la imagen del Camino de Santiago de Compostela, que, con más de doce siglos de existencia, y en el mundo occidental, atraviesa un momento de gran esplendor y visibilidad. Cerca de trescientas mil personas al año, de diferentes creencias, nacionalidades e ideologías, se acercan a la ciudad santuario de Santiago de Compostela caminando al menos 
100 kilómetros, o desplazándose en bicicleta o a caballo más de 200. Esta realidad nos lleva a analizar los atributos y las características que siguen asegurando la permanencia de la peregrinación jacobea en el tiempo, mejor dicho, cómo un fenómeno que surgió entre los mejores exponentes de las peregrinaciones cristianas medievales ha conseguido renacer y consolidarse bajo la forma de un auténtico acontecimiento de masas en los últimos decenios (Vázquez de Parga, Lacarra y Uría, 1948; Lois y Santos, 1999; CETUR, 2007-2010).

Los estudios jacobeos han despertado el interés de distintas disciplinas, entre ellas la antropología, la geografía, la sociología y, desde luego, el estudio científico de la religión, que, más que otras, aporta elementos clarificadores, ya que la peregrinación es un acontecimiento relacionado con lo sagrado. De hecho, a la hora de investigar un espacio o un lugar sagrado, debemos considerar la interacción entre lo sacro y la religión en la creación del mismo (Claval, 1999), como también qué lo diferencia de los demás espacios o lugares por su naturaleza, valor, entorno e historia. Es sagrado porque aquí tuvo lugar algún acontecimiento divino (Eliade, 1959; Brenneman, 1993; Gesler, 1996; Stoddard y Morinis, 1997; Prorok, 1997). Según el historiador Mircea Eliade, que introdujo por primera vez la expresión lugar sagrado en su obra Patterns in Comparative Religion (1959), en el proceso de construcción del mismo, el ser humano está llamado a descubrir el lugar e interpretar su valor a través del referente simbólico. Así mismo, la religiosidad medieval se manifestaba directamente en el lugar sagrado, pero sobre todo en uno de los fenómenos sociológicos y religiosos más importantes de la edad media: la peregrinación.

Considerando que los hombres y las mujeres medievales apenas podían recurrir a los recursos cartográficos y a muchos avances científicos, otorgaban al acto de peregrinar un sentido completamente trascendente. La peregrinación era una experiencia que marcaría su paso por este mundo, a través de la cual salían de la rutina para aventurarse hacia algo desconocido. Esta condición de transición típica del peregrinaje es definida por Victor Turner (1969) con el concepto de liminalidad. El limen es un límite psicológico y cruzarlo implica desplazarse hacia otra realidad. De este modo, el peregrinaje es una experiencia entre dos niveles existenciales que, a través de la ritualidad, favorece la reflexión. Es una práctica comunitaria con una serie de componentes de transgresión de las normas institucionales (Turner, 1969, 1974; Aguilar, 2000; Richman, 2002; Ivakhiv, 2003; Ashley y Deegan, 2009; Hejduk, 2010), a partir de la cual se desarrolla el sentimiento de communitas.

Consideramos que lugares sagrados y peregrinación son dos expresiones territoriales de lo sagrado interdependientes entre ellas, ya que los primeros marcan la ruta y el peregrinaje es fundamental para la esencia y el significado de los lugares sagrados. Cualquier lugar sagrado cuenta con un mito de origen, y en el caso compostelano éste reside en el inventio del hallazgo de los restos del apóstol Santiago el Mayor y de los de sus discípulos en el siglo IX ${ }^{1}$; aunque

1. Se conoce como inventio, o primera inventio, el proceso por el cual el obispo de Iria Flavia (cerca de Santiago), Teodomiro, narra el descubrimiento de los restos del apóstol en un 
la difusión de su veneración en Santiago de Compostela, su consolidación y acreditación acontecieron durante el siglo XII. El hallazgo fue el punto de partida para la fundación de un nuevo lugar sagrado en la geografía de la Europa católica, que se identificaba por su topografía, su componente humano y su sistema cultural religioso (Lopez, 2011). Por lo que se refiere al camino de peregrinación, aprovechando las rutas ya existentes, tuvo lugar un primer proceso de resemantización de las mismas, a través de la dotación de referentes simbólicos, valores y sentidos. En definitiva, se produjo una sacralización y una modelación del paisaje europeo medieval que reflejaba una concepción teológica y una imagen del mundo cristiano religioso. Este proceso demuestra cómo la religión fue capaz de convertir una dimensión subjetivo-interior en objetivo-exterior, "externalizando» sus imágenes y sus señas en construcciones y estructuras que se convierten en símbolos culturales (Cosgrove y Daniels, 1988; Claval, 1999; Kramsch, 1999), que han propiciado la reconceptualización del espacio en sentido "sagrado». De hecho, también el ser humano ha nutrido (y nutre) el valor sagrado del espacio a través de sus performances de la peregrinación, es decir, ritos y gestas.

En este trabajo, trataremos de aproximarnos a la permanencia de la peregrinación a Santiago, las distancias que marcan dicho acontecimiento entre la edad media y el período contemporáneo. Nos disponemos a analizar la idea de la polisemia del Camino desde la edad media hasta la actualidad, las causas del renacimiento contemporáneo del mismo, su doble carácter turístico como fuente de negocio y peregrino-experiencial, para finalizar interrogándonos sobre la vigencia del Camino y su autenticidad en clave contemporánea. Para este fin, creemos que es suficiente contar con el bagaje del geógrafo cultural y turístico, apoyado por las aportaciones de otras ciencias sociales vecinas (Claval, 1999).

\section{El Camino de Santiago: un escenario para la historia}

En el marco del lenguaje simbólico religioso, el rito es un símbolo formado por componentes distintos (Croatto, 2002), según la cultura y el entorno físico, con repercusiones en la vida religiosa. En el caso del Camino jacobeo, las personas tanto del medievo como de los siglos Xx y xxI tuvieron y tienen que cumplir con el ritual de la preparación. Una preparación que, desde el siglo $\mathrm{x}$ hasta el siglo Xv, se asociaba más a las ideas de penitencia, incertidumbre en el resultado y excitación transgresora en los actos religiosos y festivales en los que se participaba, y que, en épocas recientes, se vincula más a la idea de período

campus stellae, cerca de la localización actual de la ciudad. El obispo escribe un texto falso haciéndose pasar por el patriarca de Jerusalén, aludiendo a la predicación de Santiago el Mayor en la Gallaecia en período romano y el traslado posterior de sus restos desde Jaffa hasta la costa gallega para ser enterrados. La localización del santuario se produjo a 20 kilómetros de la línea litoral por cuestiones de seguridad: se pretendía evitar los ataques de vikingos y normandos, muy frecuentes en los siglos viII al x. A partir de la inventio, comienzan las peregrinaciones a Santiago. 
vacacional, descanso, contacto con la naturaleza y creación de redes de amistad (Caillois, 1939; Hejduk, 2010).

La cultura medieval se sirvió del culto que, a través de sus distintas expresiones (celebraciones o producciones artísticas), facilitó marcar en la memoria elementos culturales o ritos, además de crear un auténtico espacio sagrado, enriquecido con ciudades, catedrales, ermitas, puentes y fuentes santas (Raffestin, 1980). Toda la edad media fue una época de proliferación de cultos (Caló Mariani, 2009) que, por un lado, eran representativos de un lugar y, por otro lado, se «movían» a lo largo de las rutas de peregrinación. Entre ellos, el culto a las reliquias adquirió un papel central, en cuanto ayudó a la iglesia a imponer sus nuevas lógicas territoriales «a través de y para su poder» (Lopez, 2011). Como consecuencia, la Europa Occidental se vio constelada de lugares santos donde venerar algo (cierto o inventado); así mismo, el Camino responde a esta concepción organizada y sagrada del espacio, las estrellas (los hitos santos) que conducen a la meta de Santiago de Compostela, tercera Ciudad Santa de la cristiandad junto a Roma y Jerusalén por albergar los restos de un apóstol. Esta meta universal se convirtió en el punto final de una ramificación de rutas y de caminos que vertebraban toda Europa (figura 1), tanto en el sentido territorial, en cuanto la recorrían por completo, cuanto en el sentido religioso. El valor más importante que resultó de este proceso fue la creación de una identidad europea occidental, como afirmó siglos más tarde Goethe: «Europa se construyó caminando a Santiago».

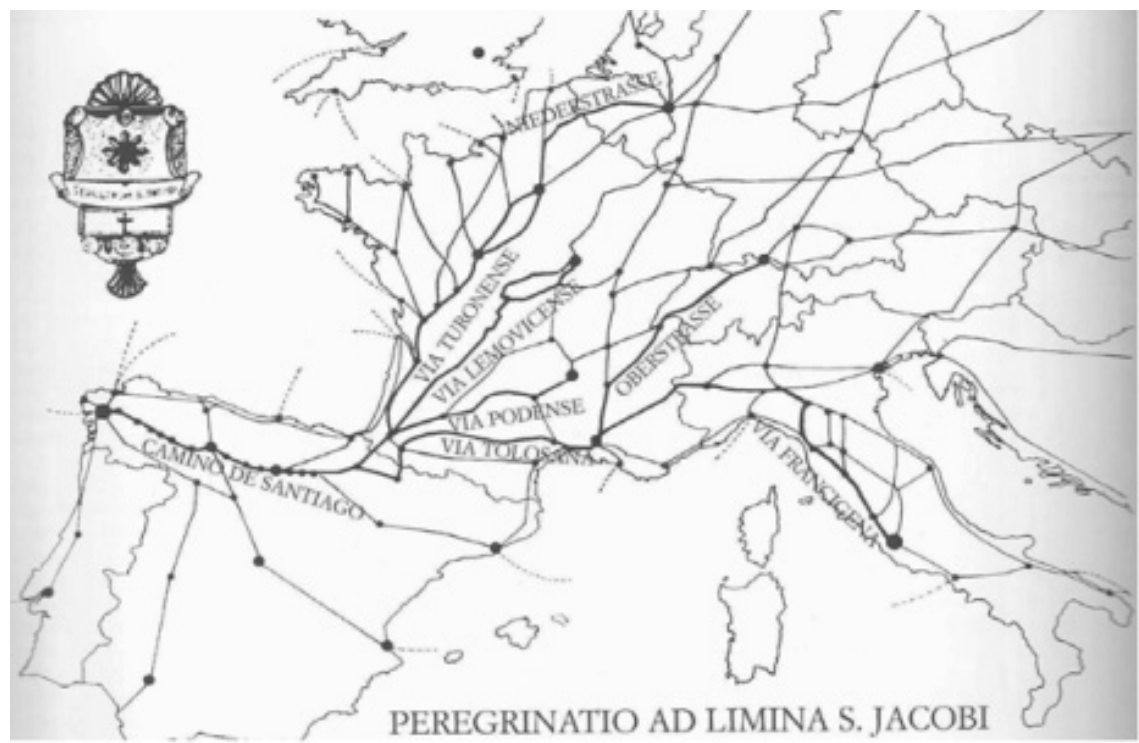

Figura 1. Los caminos vertebradores hacia Santiago de Compostela. Fuente: CAUCCI vON SAUCKEn, P. (1989). Guida del Pellegrino di Santiago. 
Entre los autores, resulta frecuente afirmar que la peregrinación era una experiencia existencial difícil, pero para muchos necesaria. De hecho, marcaba un momento importante en la vida de los hombres y las mujeres medievales, quienes, además de motivaciones exclusivamente religiosas y espirituales, también compartían otras más profanas, como, por ejemplo, evadirse de la vida cotidiana o satisfacer la curiosidad aprovechando la posibilidad de visitar otros pueblos situados a lo largo de la ruta o conocer a gentes diferentes. La llegada a la meta santuario implicaba la remisión de todos los pecados y el comienzo de una nueva etapa en lo espiritual. En otros casos, hacer el peregrinaje era una excusa para interrumpir cualquier asunto judicial (Plötz, 1995) y, desde la segunda mitad del siglo XIV, se afirmó la práctica del peregrinaje caballeresco como búsqueda de aventura. Por otro lado, los peregrinajes se convirtieron en viajes tradicionales de familias nobles (Cherubini, 1998).

Con el paso del tiempo, la idea del Camino ha evolucionado de acuerdo con un cambio cultural moderno, y desde el Renacimiento se ha puesto de manifiesto el aspecto paisajístico del mismo, ya no sólo como un recorrido por santuarios, sino como un paisaje cultural construido sobre un espacio sagrado. Un paisaje cultural con los atributos definidos por autores como Cosgrove (1998), Collignon (1999), Kramsch (1999), Roger (2007) y, de una forma indirecta, Farinelli (2009). Un paisaje que se singulariza por cuatro caracteres principales: 1) la cultura y la identidad que el fenómeno de peregrinación jacobea otorga; 2) la territorialidad, referida a las cartografías del Camino; 3 ) la historia, su permanencia a lo largo de los siglos, y 4) el poder, reflejado por la producción del espacio, primero, por la Iglesia y, en los últimos tiempos, por las autoridades políticas, que tratan de reforzar el atractivo del Camino a través de estudiados procesos de patrimonialización y exaltación de los lugares y las naciones (Castro et al., 2010).

Todos los estudios del Camino establecen un contraste entre el período medieval de peregrinación y el período contemporáneo. Esto significa que los siglos intermedios entre ambas épocas (del siglo XV al xIx) fueron de intensa crisis del fenómeno jacobeo. Por una parte, las doctrinas de Erasmo de Rotterdam y de la Reforma protestante condenaron las manifestaciones externas de la Iglesia y, en consecuencia, las peregrinaciones y el culto a las reliquias. El Camino a Santiago se quedó sin buena parte de los alemanes, holandeses y británicos que, en las centurias finales de la edad media se habían desplazado en elevado número a Compostela. También los continuos conflictos internacionales en los que se vio envuelta la Corona de Castilla en los siglos Xvi y XVII, en especial con el vecino Reino de Francia, hicieron desaparecer casi por completo los peregrinos de esa nacionalidad. Con la Contrarreforma católica impulsada por el Concilio de Trento, el flujo de viajeros a Santiago se intensificó puntualmente en el sur de Europa; el Camino se convirtió en un asunto de italianos (figura 2) e ibéricos que afirmaban sus ritos de peregrinación, culto a los santos y visitas a los lugares sagrados como forma de combate contra las herejías luterana y calvinista. En todo caso, el Camino fue declinando de forma continua hasta el siglo XIX, cuando prácticamente había desaparecido y 


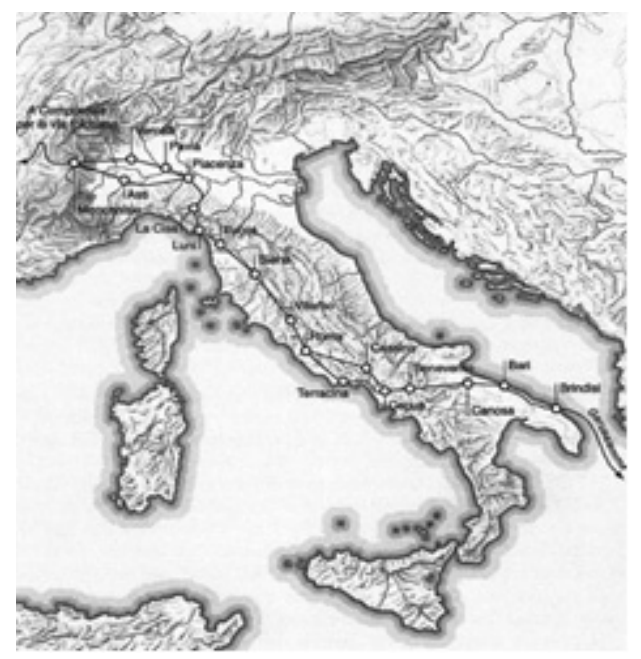

Figura 2. Los itinerarios italianos hacia Santiago de Compostela. Fuente: STOPANI, Renato (2001). Il «Camino» Italiano per Santiago de Compostela.

la propia imagen del Santiago apóstol sufrió una transformación iconográfica, de santo peregrino (acorde con la representación medieval y contemporánea) a santo guerrero que lucha contra el infiel (sea musulmán, protestante, indio, portugués en el periodo de la Guerra de Independencia de este país, etc.). Esta crisis de lo peregrino todavía justifica que, en la América hispana colonizada de los siglos XVI al XVIII, apenas tengamos imágenes del santo como caminante, frente a una proliferación del Santiago a caballo y espada en mano combatiendo a los no católicos y a los extranjeros.

Los primeros movimientos de recuperación de Santiago de Compostela como un centro de peregrinación se plantearon durante la segunda mitad del siglo XIX e, ideológicamente, enlazaban con el espíritu contrarreformista y guerrero de Trento. En este período, un canónigo, Antonio López Ferreiro, tradicionalista, romántico y experto en la historia de la catedral, es autorizado a realizar unas excavaciones en el templo y afirma encontrar los restos del apóstol. Unos restos que se sabía estaban en el edificio, pero que, según la leyenda, habían sido profundamente escondidos para evitar que las incursiones musulmanas los robasen o destruyesen. Inmediatamente, la Iglesia católica dio por bueno el descubrimiento que, en la historiografía compostelana, se identifica como la segunda inventio ${ }^{2}$. En el fondo de todo este acontecimiento, estaba el apoyo que el cardenal de Santiago realizó a la infalibilidad del papado en

2. La segunda inventio alude al proceso de redescubrimiento de los restos del apóstol Santiago en el siglo XIX, en época del canónigo e historiador A. López Ferreiro y del cardenal Payá, bastión de las posiciones más tradicionalistas de la Iglesia y defensor a ultranza de la infalibilidad del papa. Los restos del apóstol, descubiertos tras su ocultación desde la edad media, nunca fueron examinados científicamente para acreditar su autenticidad. 
esos momentos a discusión (un curioso y excepcional acuerdo entre la iglesia de Roma y la de Santiago, muchas veces competidoras). Las peregrinaciones hacia la catedral se recuperan como visitas desde parroquias más o menos cercanas, en un movimiento de iglesia popular que desde el Papa León XIII se intentó impulsar en el catolicismo. Estas peregrinaciones también suponían la afirmación conservadora y militante del mito de Santiago contra las tentaciones liberales de muchos gobiernos de España en estos decenios; por supuesto, una afirmación de España (junto con Italia) como la gran nación católica del mundo, básica en la evangelización de América, y deseosa de preservar sin cambios sus tradiciones. En este contexto de apropiación reaccionaria de Santiago y la peregrinación renaciente, el lema «Santiago y cierra España» resume una idea que combina catolicidad, aislamiento y la mezcla del Santiago guerrero con el peregrino.

Sin lugar a dudas, un segundo impulso de gran significación a las peregrinaciones compostelanas fue el dado por el general Franco. De nuevo, Santiago como un mito ultraconservador utilizado por el dictador salido de la Guerra Civil en sus años (1939-1953) de mayor aislamiento internacional y, por consiguiente, de afirmación del nacionalcatolicismo. Según la propaganda del régimen, la Guerra Civil (1936-1939) no había sido el resultado de un golpe de estado fracasado que había degenerado en una larga contienda, sino una cruzada contra los ateos, el comunismo y la masonería. Una cruzada nacional donde la imagen del Santiago guerrero se había aliado con las tropas de Franco para conducirlas a la victoria final. De este modo, Santiago fue encumbrado a "patrono de las Españas» y el gobierno de Franco se volcó con la monumentalización historicista de la propia ciudad de Santiago y algunos de los hitos más destacados de su Camino (Castro, 2010). España estaba identificada por el primer franquismo como «la reserva espiritual de occidente»; el Camino de Santiago, como la expresión sagrada y material de esta idea, y la ciudad de Santiago, como el origen de una interpretación aislacionista y ultracatólica de la identidad nacional.

La polisemia de Santiago y de su Camino ha sido una constante a lo largo de su historia. Así, frente a un discurso nacionalista, autárquico e integrista en lo religioso de la época de Franco, con la llegada de la democracia, el fenómeno jacobeo, lejos de debilitarse, ha conocido un nuevo período dorado, en este caso con unos referentes más abiertos, contemporáneos y diversos. El Santiago guerrero ha dejado definitivamente paso al Santiago peregrino y una coalición de estudiosos del Camino, asociaciones de amigos de Santiago distribuidas por toda Europa y administraciones públicas deseosas de favorecer la promoción turística de sus ciudades y regiones en clave cultural e histórica, han construido un potente movimiento que justifica el éxito presente del Camino de Santiago, de lo jacobeo en general ${ }^{3}$. El pilar ideológico que, desde finales de la década de

3. Jacobeo, en español, o xacobeo, en gallego, son calificativos para referirse al culto y a la peregrinación a Santiago. Toman como referencia el nombre Iacobus, Iago, Jaume, Diego o James, equivalentes a Santiago según la transcripción de las lenguas clásicas que se realice. 
1970 , sostiene este edificio es muy claro. Primero, se ha reemplazado por completo el discurso autoritario sobre la peregrinación a Santiago y se ha ensalzado el carácter europeo del Camino desde la edad media. El recurso a las citas de Dante, Goethe o Joyce a Compostela se ha repetido para vincular el reconocimiento de Santiago como Patrimonio de la Humanidad de la UNESCO en 1985, con la integración de España en la Comunidad Europea en 1986, la declaración del Camino como Primer Itinerario Cultural Europeo del 1987 y de todo el Camino como Patrimonio de la Humanidad en 1993.

\section{¿Espacio sagrado o espacio turístico? Espacio polisémico}

El renacimiento de la ruta multiidentitaria del Camino se acompaña de un renovado perfil de quien lo recorre. Hoy se habla de "peregrino secular" para referirse al hombre postmoderno en búsqueda de su identidad (Digance, 2003). Como consecuencia, florecen religiones de tipo privatizado, en las cuales el poder reside en el individuo y no en lo trascendente (Farias y Lalljee, 2008), son los movimientos New Age, que, a partir de las décadas de 1960 y 1970, interpretan el deseo de una nueva «autoespiritualidad» (Digance, 2003). Las nuevas religiones seculares o civiles, fundadas en sentimientos nacionalistas, continúan legitimando la realidad a través de nuevos lugares de adoración (Mazumdar y Mazumdar, 2004) y fomentan nuevas peregrinaciones hacia lugares de memorias o tumbas de mártires nacionales, o conmemoran la diáspora (root-pilgrimage o diáspora tourism) para recuperar las raíces étnicas de una población (Wagner, 1997; Basu, 2004). Desde luego, es inevitable que personas de distintas confesiones compartan un mismo espacio. Ello da origen a un proceso de continua resemantización del mismo, en función de sus interacciones y de las acciones en el territorio. Este es el caso del Camino de Santiago, una ruta histórica que se enfrenta a unos desafíos que son cuestionados por la sociedad contemporánea, es decir, por un lado, tiene que guardar su legado europeo cristiano, pero «sufre» los cambios contemporáneos junto con las transformaciones sociales y las nuevas modalidades de la movilidad. Entre éstas, nos disponemos a prestar atención a uno de los fenómenos sociológicos más debatidos y analizados de los últimos años: el turismo. Intentaremos reflexionar sobre los aspectos que diferencian y acomunan la peregrinación y el turismo.

La palabra peregrinación define el viaje religioso (o simplemente espiritual) de una persona o un grupo a un santuario o lugar sagrado, si bien la palabra

De hecho, xacobeo se ha convertido en una referencia turística de primera magnitud, pues alude a la celebración de los años santos (cuando la fiesta de Santiago coincide en domingo, se amplían las indulgencias de la Iglesia y las administraciones públicas españolas lanzan grandes campañas promocionales del Camino). El Xacobeo también es el nombre de una empresa pública de la comunidad autónoma de Galicia para la difusión del Camino de Santiago, y Consejo Jacobeo es un organismo de coordinación entre el Gobierno español y las autonomías atravesadas por el Camino para conservar su valor histórico-cultural y realizar campañas de difusión de sus valores patrimoniales. 
procede del latín peregrinus, que hace referencia a quien, a través de los campos (per agrum o per agere), llegaba a la civitas romana desde otra comunidad política (García Cantero, 2010) y acabó designando a quien va o viene del extranjero (Caucci von Saucken, 1989, 1993a; Agís Villaverde, 2008) y al hombre de viaje, sin derecho de ciudadanía (Oursel, 1978), es decir, un extranjero desconocido, por el que no responde nadie y que, procediendo de otra realidad, es portador de inquietud (Hernando, 2007). Por otro lado, el término turista procede del latín tornus, para indicar quien hace un viaje circular para diversión y vuelve al punto inicial (Smith, 1992).

Algunos autores (Cohen, 1992; Trunbull, 1992) afirman la separación entre el turismo y la peregrinación con respecto a factores determinados que hemos resumido como sigue:

- Obligatoriedad: el peregrinaje es una actividad más o menos obligatoria, mientras que el turismo es una actividad de diversión.

- Institucionalización: el peregrinaje está institucionalizado a través de normas y ritos (Cohen, 1992; Berger, 1971), su significado está culturalmente reconocido, a diferencia del turismo, que es a menudo asociado a algo frívolo y superficial.

- Movimientos: el peregrinaje es un movimiento hacia el centro, fuente del orden santificado del cosmos y sede del poder divino (Turner y Turner, 1978), mientras que el turismo es un movimiento hacia lo Otro, o sea la dimensión del turista, más ambigua. Finalmente, el itinerario del peregrinaje y la dirección de su movimiento tienen un valor simbólico (Morinis, 1992), mientras que el turismo moderno no está vinculado a rutas y direcciones.

- Estación: en el caso del peregrinaje, tradiciones religiosas y temporadas están relacionadas en función del santuario y de la región. Por lo contrario, la actividad turística puede tener lugar en cualquier momento, según el deseo de la persona.

- Motivaciones: los peregrinos viajan por motivaciones básicamente espirituales y los turistas, por motivaciones seculares.

- Esquemas de conducta: el peregrinaje presupone una modalidad existencial, por lo tanto, el peregrino debe respetar un conjunto simbólico del comportamiento, a diferencia del turista, cuyo comportamiento presenta modalidades recreativas y diversivas.

- Relaciones con coviajeros: turistas y peregrinos intentan viajar con alguien, pero el valor de la compañía cambia según el viaje. Para el peregrino, el grupo es parte de la experiencia (communitas).

- Dimensión interior del sujeto a sus emociones: el poder sagrado es capaz de transformar el individuo, el turista tiende a enfatizar la naturaleza social y secular de la búsqueda.

Si trasladamos estos factores al Camino de Santiago, destacamos cuales serían los atributos de esta peregrinación viaje contemporáneo: su instituciona- 
lización, a través de una vía definida y delimitada, con unos niveles de fidelidad al destino muy destacados (CETUR, 2007-2010; Croes et al., 2010), cuyo recorrido se acompaña de la realización de una serie de ritos característicos; el movimiento hacia una meta o destino claramente reconocible; la motivación, siempre asociada a contenidos espirituales, de encuentro con uno mismo, y unos esquemas de conducta particulares, entre los que destacan las relaciones con otros viajeros que hacen la misma ruta (Cohen, 1992; Turnbull, 1992; Morinis, 1992).

Desde un punto de vista teórico, las dinámicas de turismo y peregrinación están relacionadas, ya que se suele considerar el turismo una metamorfosis moderna de la peregrinación en el sentido secular del término (Collins-Kreiner, 2010), y con esto también han sido secularizados los significados simbólicos de muchos lugares (Greed, 2011; Cloke, 2011; Ashworth, 2011), que se transforman en simples sitios turísticos. En la figura 3, mostramos un esquema en favor de dicha "convergencia» que Mary Lee Nolan y Sidney Nolan aportan en su obra (1989), fruto de una investigación decenal sobre los santuarios europeos. En este esquema interpretativo, se visualizan las interacciones establecidas entre las tres tipologías de espacios:

I. La primera tipología de espacio se refiere al santuario de peregrinación.

II. La segunda tipología se refiere a un espacio que presenta una atracción turística religiosa, como, por ejemplo, patrimonio artístico e histórico; por lo tanto, hacia la cual se dirigen ambos, turistas y peregrinos.

III. La tercera tipología es un espacio donde tienen lugar fiestas religiosas o procesiones. Son espacios numerosos en Europa, aunque no metas de peregrinaciones. Desde luego, atraen a fieles y a turistas.

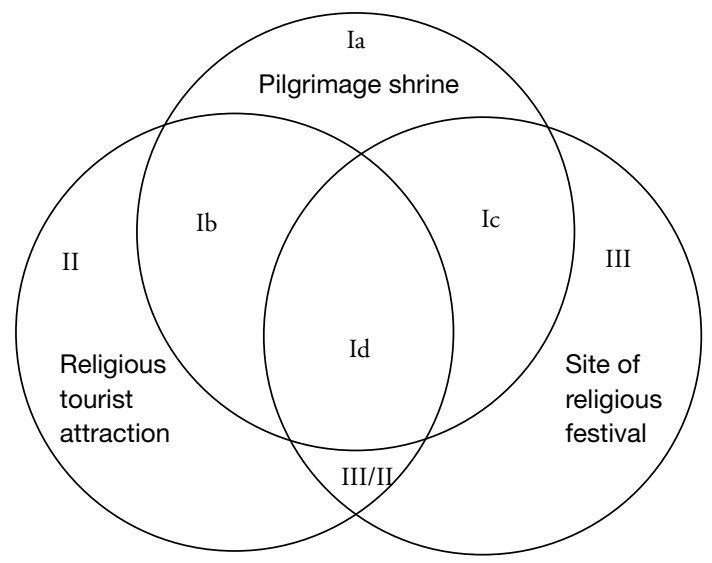

Figura 3. Relaciones entre santuarios, atracciones turístico-religiosas y lugares de festivales religiosos. Fuente: Nolan, M. y NoLAN, S. (1989). Christian Pilgrimage in Modern Western Europe. 
Según se solape con otros, el espacio puede ser: 1a) únicamente sagrado, por lo tanto, es poco relevante desde el punto de vista turístico; 1b) espacio sagrado con atracciones turísticas que lo hacen importante para el turismo, así que el número de turistas supera el número de peregrinos; 1c) espacio sagrado que coincide con el de una fiesta religiosa, que es el evento más importarte de todo el año; $1 d$ ) en este espacio sagrado coincide la presencia de un santuario, de atracciones turísticas y de una fiesta religiosa anual; así mismo, se registra una afluencia turística constante a lo largo de todo el año y el evento que suscita más atracción es la fiesta del santo patrón, como Santiago de Compostela (II y III), que se trata de un espacio donde tiene lugar una fiesta religiosa y que presenta atracciones turísticas.

Es evidente que los límites entre peregrinaje y turismo no están bien marcados. Un peregrino puede estar tan interesado en visitar una iglesia como puede estarlo un turista (Davie, 2000) y esto porque se considera el turismo religioso como un subgrupo del turismo cultural (Rinschede, 1992). Sin embargo, el turismo religioso tiene pocas implicaciones teológicas y tradicionales con respecto al término peregrinaje, ya que abarca motivaciones también asociadas a historia religiosa, arte y devoción. Por lo tanto, en un espacio sagrado se puede encontrar una variedad de visitantes: peregrinos (solos o en grupo) o turistas peregrinos; todos unidos por una satisfacción personal; buscan algo aunque en los simples viajeros esa experiencia pueda ser completamente secular. Por lo tanto, una y otra categoría aparecen perfectamente entrelazadas. Por ejemplo: a su llegada a Santiago, muchos peregrinos se transforman en turistas que desean

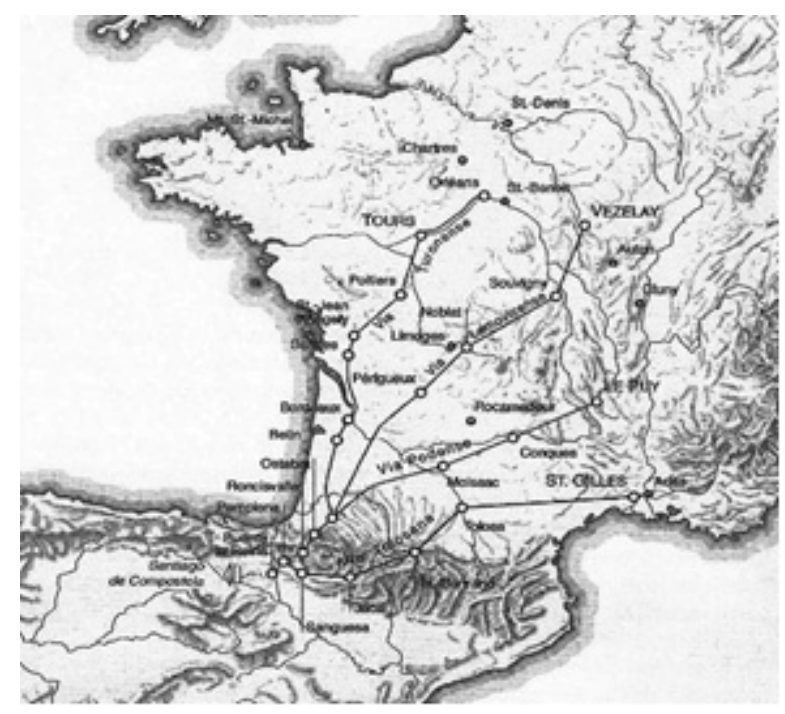

Figura 4. Los itinerarios franceses hacia Santiago de Compostela. Fuente: STOPANI, Renato (2001). Il «Camino» Italiano per Santiago de Compostela. 
conocer la región y se comienzan a comportar como visitantes convencionales (Frey, 1998). Se peregrina todavía y sobre todo desde otras partes de España, si bien el éxito del Camino es notable en Alemania, más vinculado a su componente estrictamente religioso en Italia, mientras que franceses, holandeses, británicos, brasileños y norteamericanos también constituyen contingentes representativos de viajeros hacia Santiago.

Como acabamos de analizar, peregrinaje y turismo (religioso o cultural) comparten un mismo espacio, cuyo valor añadido es una riqueza de recursos (materiales e inmateriales) que nutre su polisemia. Este es evidente en el caso de los territorios que se construyen y afirman a partir del Camino y que se han yuxtapuesto en su renacimiento contemporáneo, polisémico y postmoderno (Possamai, 2003). Es un espacio que cumple con distintas funciones: define un espacio sagrado, una vía de peregrinación actual y una ruta del turismo cultural de primera magnitud de la cual se conoce su meta, pero no está claro su inicio. $\mathrm{Si}$ interpretamos el Camino en clave de Europa, el mismo comienza en Le Puy (figura 5), en Vezelay, en Dingle y, cada vez de manera más frecuente, en Saint Jean de Pied de Port (en la Navarra francesa), del otro lado del Pirineo, lo cual trata de indicar que la vía hacia Compostela no es exclusivamente ibérica.

El Camino se ha cuidado y se ha patrimonializado de forma notable en Navarra y La Rioja, pequeñas comunidades autónomas españolas, con numerosas poblaciones y tradiciones de origen medieval, que se reinventan y crean una imagen de prestigio a través de lo jacobeo. La propia riqueza gastronómica y vinícola de ambos territorios ha conseguido transmitirse de forma muy efectiva al exterior gracias a la excelente plataforma turística que constituye el Camino. Del mismo modo, ciudades con centros históricos y monumentos muy valiosos

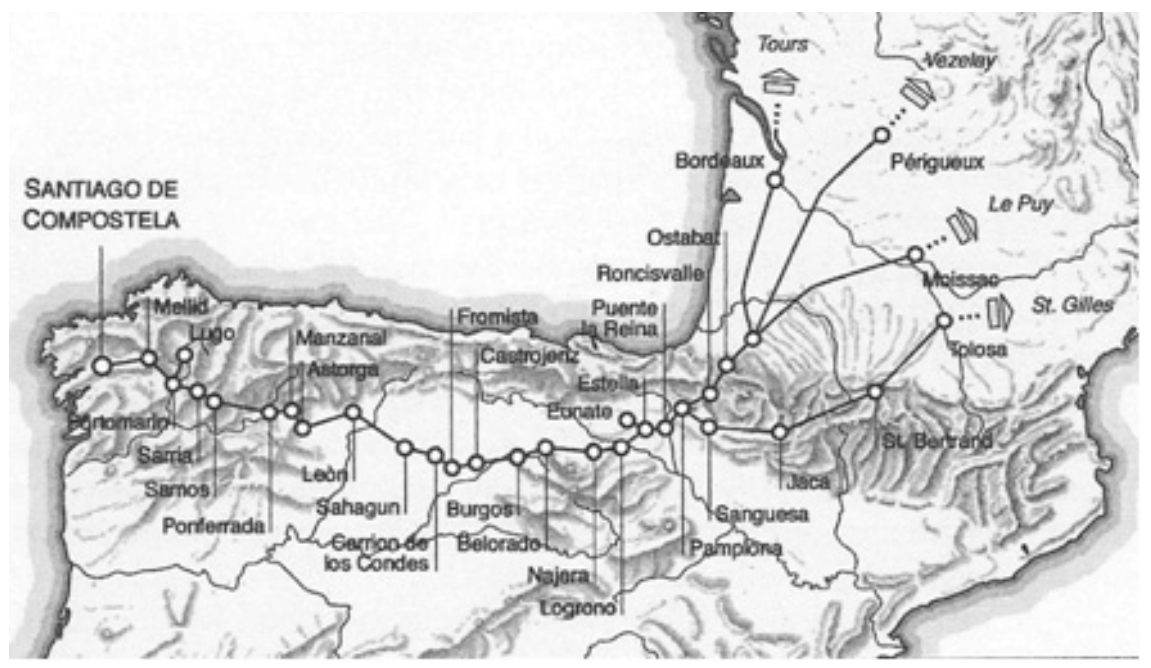

Figura 5. Los itinerarios de los peregrinos jacobeos en España. Fuente: STOPANI, Renato (2001). Il «Camino» Italiano per Santiago de Compostela. 
(Burgos, Santo Domingo de la Calzada, Astorga, Sahagún, León, etc.), pero que hasta hace poco no habían optado por políticas serias de rehabilitación, se han embellecido y transformado aprovechando el impulso generado por la ruta jacobea (Lois, 2000; Lois y Somoza, 2003). En numerosos trabajos, también se ha insistido que la construcción de una imagen regional o nacional fuerte en Galicia, territorio atlántico del noroeste peninsular creado a partir de la importancia del santuario compostelano, obedece al enorme prestigio actual que ha alcanzado el Camino de Santiago (Santomil, 2011). En definitiva, Santiago de Compostela y su Camino se afirman como modelo de los destinos de turismo histórico-cultural (espiritual y religioso) del presente (Huh et al., 2006); actúan a modo de ejemplos a seguir, tanto por parte de las ciudades monumentales que aspiran a convertirse en Patrimonio de la Humanidad como por los itinerarios culturales que están proliferando por Europa en los últimos tiempos.

\section{El peregrino en la actualidad: entre legado del pasado y emociones contemporáneas}

$\mathrm{Si}$, por un lado, la estructura de la peregrinación sigue siendo la misma, ya que los hombres y las mujeres medievales que peregrinaban a Santiago, las autoridades políticas y religiosas que utilizaban las imágenes del apóstol contra los herejes y el peregrino turista jacobeo contemporáneo emplean los mismos referentes míticos y culturales o atraviesan las mismas ciudades y calzadas, los contenidos cambian, porque cambian las épocas históricas. A continuación, avanzamos tres claves de lectura para el peregrino contemporáneo:

- Los ritmos del Camino.

- El paisaje.

— La dimensión social.

\section{Los ritmos del Camino}

A lo largo del Camino, el paso del tiempo está marcado por el sol, el atardecer, es decir, por la luz. A ésta última, el peregrino debe adecuar el ritmo de su andar, que está también determinado por su motivación, su disposición interior y por la admiración por lo nuevo, que descubre asomándose a «la ventana» (Lefebvre, 1996). Aunque Henri Lefebvre emplea la metáfora de la ventana como metodología para descubrir los ritmos de la ciudad (en concreto del centro de París), nosotros la tomamos en préstamo para aludir al acto de «ver» del peregrino, cuya mirada sobre el Camino es hoy más atenta. De hecho, la experiencia del peregrinaje no coincide con su comienzo, sino que se inicia antes, cuando la decisión de hacer el peregrinaje pone en marcha un mecanismo de información a través del cual se «abre una ventana» sobre el mundo camino. Por estas razones, el peregrino actual suele estar muy informado, también gracias a la ayuda de asociaciones o cofradías jacobeas (Caucci von Saucken, 1993b), que facilitan la posibilidad de realizar las rutas de pere- 
grinación todos los años. Sin embargo, esta preparación al Camino se concreta también en la preparación física y psicológica, que se hace necesaria cuando el peregrino decide recorrerlo de forma íntegra desde Roncesvalles o cuando planea la peregrinación como una experiencia deportiva.

Además de los conocidos ritmos visibles del Camino, que también representan un enlace con el pasado (como el vestido, la confesión o la visita a la tumba del apóstol), existen ritmos interiores, cuya investigación es hoy facilitada por el interés de la antropología (Claval, 1999). Los ritmos interiores (o escondidos) se caracterizan por sentimientos y emociones, como, por ejemplo: la solidaridad, el sentimiento de dependencia, el desapego al lugar y al tiempo, la comunión con la naturaleza y el descentramiento del yo en lugar del tu. Resultan de la interrelación entre disposición interior y momentos del camino, como, por ejemplo: las emociones de triunfo que se advierten a la hora de llegar a Santiago; pero si se ha recorrido el camino para encontrar alguna respuesta, el acercamiento o la llegada al destino final puede causar inquietud interior.

Debido a su intensidad y originalidad, se suele asociar la peregrinación a Santiago a un particular viaje interior que propicia un descanso emocional, muy valorado por el ser humano contemporáneo, sometido a la rapidez y a la intensidad de la vida en las grandes ciudades, y que durante sus vacaciones busca algo original, que le aporte un cambio. Como en el pasado, la movilidad de la ruta se concilia con una ocasión de reflexión, pero si consideramos que hoy en día los únicos en recorrerlos, y aún por encima de forma auténtica, son los peregrinos (religiosos o seculares) o los peregrinos turistas, podríamos afirmar que el camino se está descubriendo a sí mismo, haciendo que los "caminantes» no tengan que compartir este espacio polisémico y multiconfesional con mercantes. En definitiva, hoy el Camino, tanto a nivel emocional cuanto a nivel territorial, es más auténtico que en el pasado; sigue asegurando una liberación de la estructuración social diaria (Turner y Turner, 1978) del peregrinaje y nutriendo el sentido de communitas.

\section{El paisaje}

El peregrino medieval no poseía una sensibilidad hacia el paisaje, de hecho, en la Guía del Peregrino Medieval del Calixtino (Xunta de Galicia, 1992), no se realizan descripciones ni de los paisajes ni de las cualidades estéticas de los lugares visitados. Por el contrario, el peregrino (post)contemporáneo posee una conciencia y una sensibilidad "paisajística» que le permite ser más sensible hacia este elemento significante del pasado y del presente, enriquecido con una herencia patrimonial histórica y cultural siempre más valorada. Dicha "conciencia paisajística» es un elemento distintivo de la misma experiencia del camino, en cuanto la forma de verlo o de percibirlo cambia al tener que estar en contacto directo con él, ya que el peregrino es un viandante que, al andar, cambia de "paisaje» (en el sentido más amplio del término) y, por lo tanto, ve el mundo con ojos siempre nuevos (Rigobello, 2003). 


\section{La dimensión social}

El bagaje emocional y personal con el cual un peregrino viaja son determinantes para su experiencia y para las interacciones con los demás peregrinos $\mathrm{u}$ operadores del camino. Como hemos analizado a lo largo de este trabajo, hoy la peregrinación está siendo siempre más articulada y rica, por eso el foco de atención se desplaza a las interacciones sociales, que semantizan y transforman el espacio del Camino a través de contactos y acontecimientos. Durante su consolidación democrática de los últimos decenios, el Camino se ha convertido en un espacio plural, en un contexto de diversidad de creencias, culturas y escalas de valores, donde la multiculturalidad es un atributo incuestionable de lo jacobeo. Por último, la ruta de peregrinación ha generado nuevas diferencias en el valor del espacio recorrido, en especial del espacio urbano, ya que se potencian los centros históricos, donde se compra, se come y se permanece, frente a una devaluación de los paisajes banales del crecimiento edificativo del último siglo.

Además, la peregrinación jacobea se relaciona directamente con el nuevo carácter del turismo del siglo XxI, que huye de la masificación y busca la ruptura radical con la cotidianeidad. El caminante a Santiago de hoy en día es ciertamente un ciudadano turista que procura conseguir, en su marcha hacia Compostela, una experiencia de desconexión y disfrute original, pero, al mismo tiempo, los componentes emocionales, espirituales y naturalistas de la peregrinación jacobea no sólo no se han debilitado, sino que se refuerzan, tal y como coinciden en afirmar los estudios científicos sobre el turismo cultural que llega a Santiago (CETUR, 2007-2010).

\section{Conclusiones}

A través de nuestro trabajo, hemos puesto de manifiesto el conjunto de dimensiones y significados del Camino de Santiago que refuerza su carácter polisémico y, por lo tanto, la principal razón de su permanencia en el tiempo. Como hemos indicado brevemente, cada período ha definido sus propios tipos de peregrinación y ha dotado al espacio sagrado de unos contenidos singulares, que se han ido sumando a los ya existentes y consolidando, así mismo, el espesor histórico del Camino. Por lo tanto, destacamos cinco factores clave que han contribuido a renovar el Camino a lo largo de estos siglos.

El primero atañe a la existencia de una cierta vocación militante de impulsar la ruta, gracias a la cual, desde la década de 1960, han proliferado los estudios (normalmente obra de medievalistas y filólogos) que trataban de recuperar la memoria del Camino. Los esfuerzos y el empeño, tanto de científicos y de ciertos grupos tanto religiosos como de activistas de la conservación del patrimonio o de simples caminantes, han confluido en la creación de asociaciones y confraternidades de amigos de la ruta jacobea.

El segundo elemento, y ya lo hemos apuntado, viene dado por la enorme originalidad del Camino. Una experiencia de disfrute de un espacio sagrado 
y cultural lineal, un itinerario patrimonializado cuidado y enriquecido desde las instituciones públicas consolidadas a diferentes escalas de gobierno que se debe recorrer despacio para llegar a una ciudad santa y/o Patrimonio de la Humanidad (el propio camino es Patrimonio de la UNESCO en la búsqueda de la meta monumental final).

El tercer factor está asociado directamente al anterior y hace referencia a que el Camino se ha restaurado y rehabilitado de forma integral desde la década de 1990. Por ejemplo, la rehabilitación de monasterios, iglesias y de otras estructuras del patrimonio arquitectónico del camino ha mejorado la oferta de una red de albergues y ha dinamizado el territorio. Para facilitar el camino, se han rehabilitado la pavimentación, los puentes y los pasos fluviales; para poder descansar y disfrutar del paisaje, se ha dotado a las rutas de fuentes, áreas de descanso y miradores en los puntos principales del Camino. Desde luego, se han rehabilitado cascos históricos y se han incorporado puntos de información y recepción del visitante. En la actualidad, constituye uno de los pocos ejemplos destacados de patrimonialización de un itinerario internacional en el contexto europeo. Esta actuación, con numerosas instituciones implicadas en el mismo objetivo, ha enriquecido de manera notable el valor del espacio sagrado de peregrinación, también el conjunto de lugares vivos de preservación estética, monumental y de recuperación de la historia (Castro et al., 2010).

El cuarto factor es la idoneidad del fenómeno jacobeo desde el punto de vista ideológico, por las distintas identidades territoriales que conviven en Europa. Desde la década de 1970, el Camino se ha redescubierto como argumento de reivindicación de la unidad europea occidental; una Europa en la que siempre se había integrado la península Ibérica. Como se ha indicado, el Camino está íntimamente relacionado con el proceso de construcción de una cultura cristiana y occidental en el continente; así mismo, ha sido instrumentalizado por ideologías nacionalistas y reaccionarias y, en los últimos tiempos, se suma al renacer de las identidades nacionales subestatales (tan importantes en España con los casos gallego, vasco o catalán).

Por último, el Camino contemporáneo es una experiencia de retorno a una escala más humana de las cosas, puesto que el renacimiento del Camino no podría considerarse exitoso en caso de que las gentes no hubiesen acudido a recorrerlo de forma masiva desde la década de 1990. De hecho, la peregrinación a Santiago caminando (o en bicicleta) se ha convertido en la más importante de las realizadas en Europa, con cientos de miles de personas que la protagonizan año tras año. Las razones de esta recuperación de una práctica supuestamente medieval son varias y se relacionan directamente con las necesidades de los seres humanos del presente y con las nuevas demandas del turismo. 


\section{Referencias bibliográficas}

Agís Villaverde, Marcelino (2008). «Antropología de la Peregrinación: ¿Quiénes son los peregrinos?». XI Encuentro de Santuarios de España [en línea]. <http:// www.conferenciaepiscopal.nom.es/pastoral/turismo/encuentro/XI/Turismo. pdf> [Consulta: 1 julio 2011].

Aguilar, Mario I. (2000). «Religion as culture or culture as religion?: The status quaestionis of ritual and performance». Culture and Religion, 1 (2), 233-245.

Ashley, Kathleen y Geegan, Marilyn (eds.) (2009). Being a Pilgrim: Art and Ritual on the Medieval Routes to Santiago. Lund Humphries: Farnham-Surrey.

Ashworth, Greg (2011). «Public Past in Plural Societies: Models for Management in Postsecular City». En: Beaumont, Juston y Baker, Christopher (eds.). Postsecular Cities. Space, Theory and Practice. Londres: Continuum, 168-184.

Basu, Paul (2004). «Route metaphors of "roots-tourism" in the Scottish Highland diaspora». En: Coleman, Simon y Eade, John (eds.). Reframing Pilgrimage: Cultures in Motion. Londres: Routledge, 150-174.

Berger, Peter (1971). El dosel sagrado: para una teoría sociológica de la religión. Buenos Aires: Amorrortu.

Beaumon, Juston y Baker, Christopher (2011). Postsecular Cities: Space, Theory and Practice. Londres: Continuum.

Bowman, Glenn (1991). "Christian ideology and the image of a Holy Land: The place of Jerusalem pilgrimage in the various christianities». En: EAdE, John y Sallnow, Michael J. (eds.). Contesting the Sacred: The Antropology of Christian Pilgrimage. Londres: Routledge, 98-121.

Brenneman, Walter (1993). «Pilgrimage and Place: The Reciprocal Relationship of Topographical Context and religious Image at Medjugorje». Architecture and Comportament, 9 (2), 205-212.

Caillois, Roger (1939). L'homme et le sacré. París: Folio.

Caló Mariani, Maria Stella (2009). "Il culto dei Santi sulle vie dei pellegrini e dei crociati». En: Caló Mariani, Maria Stella (ed.). I Santi venuti dal mare. Bari: Adda Editore, 291-324.

Castro Fernández, Belén Ma (2010). O redescubrimento do Camiño de Santiago por Francisco Pons Sorolla. Santiago de Compostela: Xunta de Galicia.

Castro Fernández, Belén Ma; López, Lucrezia y Piñeira Mantiñán, Ma José (eds.) (2010). Processes of Heritage Making in Geographical Space. Santiago de Compostela: Publicacións da Universdade de Santiago de Compostela.

Caucci von Saucken, Paolo (1989). Guida del Pellegrino di Santiago. Milán: Jaca Book.

- (1993a). "Vida y significado del peregrinaje a Santiago». En: CAucci von SAUCKen, Paolo (ed.). Santiago: La Europa del Peregrinaje. Barcelona: Lunwerg, 91-111.

- (1993b). «Formas y perspectivas de la peregrinación actual». En: Álvarez Gómez, Ángel (ed.). Pensamiento, Arte y Literatura en el Camino de Santiago. Santiago de Compostela: Dirección Xeral de Política Lingüística, 163-180.

CETUR (2007-2010). Observatorio estadístico do Camiño de Santiago 2007, 2008, 2009 e 2010. Universidade de Santiago de Compostela: Xunta de Galicia y Centro de Estudios Turísticos (CETUR).

Cherubini, Giovanni (1998). Santiago di Compostela: Il pellegrinaggio Medievale. Siena: Protagon Editori Toscani. 
Claval, Paul (1999). «Los fundamentos actuales de la Geografía Cultural». Documents d'Anàlisi Geogràfica, 34, 25-40.

Cloke, Paul (2011). "Emerging Postsecular Rapprochement in the Contemporary City». En: Beaumont, Juston y Baker, Chistopher (eds.). Postsecular Cities: Space, Theory and Practice. Londres: Continuum, 237-254.

Cohen, Eric (1992). «Pilgrimage and Tourism: Convergence and Divergence». En: Morinis, Alan (ed.) (1992). Sacred Journeys: The Anthropology of Christian Pilgrimage. Wesport, Connecticut: Greenwood Press, 47-61.

Coleman, Simon y Eade, John (eds.) (2004). Reframing Pilgrimage: Cultures in Motion. Londres: Routledge.

Collignon, Béatrice (1999). «La geografía cultural en Francia: un estado de la cuestión». Documents d'Anàlisi Geogràfica, 34, 103-117.

Collins-Kreiner, Noga (2010). «The Geography of Pilgrimage and Tourism: Transformations and Implications for Applied Geography». Applied Geography, 20 (1), 153-164.

Cosgrove, Denis (1998). Social Formation and Symbolic Landscape. Madison, WI: University of Wisconsin Press.

Cosgrove, Denis y Daniels, Stephen (eds.) (1988). The Iconography of Landscape. Cambridge: Cambridge University Press.

Croatto, José Severino (2002). Experiencia de lo Sagrado: Estudio de la fenomenología de la religión. Estella: Verbo Divino.

Croes, Robertico; Shani, Amir y Walls, Andrew (eds.) (2010). «The Value of Destination Loyalty: Myth or Reality?». Journal of Hospitality, Marketing and Management, 19 (2), 115-136.

Davie, Grace (2000). Religion in modern Europe: A memory mutates. Oxford: Oxford University Press.

Digance, Justine (2003). "Pilgrimage at Contested Sites». Annals of Tourism Research, 30 (1), 143-159.

Eliade, Mircea (1959). Patterns in Comparative Religion. Nueva York: Meridian.

Farias, Miguel y Lalljee, Mansur (2008). "Holistic Individualism in the Age of Aquarius: Measuring Individualism/Collectivism in New Age, Catholic, and Atheist/Agnostic Groups». Journal for the Scientific Study of Religion, 47 (2), 277-289.

Farinelli, Franco (2009). "El don de Humboldt: el Concepto de Paisaje». En: CopeTA, Clara y Lois, Rubén C. (eds.). Geografía, Paisaje e Identidad. Madrid: Biblioteca Nueva, 263-292.

Frey, Nancy (1998). Pilgrim Stories: On and Off the Road to Santiago. Berkeley, CA: University of California Press.

García Cantero, Gabriel (2010). «Ruta Jacobea, jus commune y jus europeum». Revista de Derecho UNED, 7, 307-324.

Gesler, Wil (1996). "Lourdes: Healing in a place of pilgrimage». Health and Place, 2 (2), 95-105.

Greed, Clara (2011). "A Feminist Critique of the Postsecular City: God and Gender». En: Beaumont, Juston y Baker, Christopher (eds.). Postsecular Cities: Space, Theory and Practice. Londres: Continuum, 104-120.

Hejduk, Renata (2010). «Step into liquid: Rites, transcendence and transgression in the modern construction of the social sacred». Culture and Religion, 11 (3), 277-293.

Hernando, Joseph (2007). «La peregrinación, camino de esperanza». En: El cami de Sant Jaume i Catalunya. Barcelona: Abadia de Montserrat, CSIC, 83-89. 
Huh, Jin; Uysal, Muzaffer y Mccleary, Ken (eds.) (2006). «Cultural/Heritage Destinations: Tourist Satisfaction and Market Segmentation». Journal of Hospitality, Marketing and Management, 14 (3), 81-99.

Ivakhiv, Adrian (2003). "Nature and Self in New Age Pilgrimage». Culture and Religion, 4 (1), 93-118.

KramsCh, Olivier Thomas (1999). "El horizonte de la nueva geografía cultural». Documents d'Anàlisi Geogràfica, 34, 53-68.

Lefebvre, Henri (1996). Writings on Cities. Oxford: Blackwell.

Lois González, Rubén C. (2000). «Dotaciones e infraestructuras del Camino de Santiago: Una aproximación geográfica». En: López Trigal, Lorenzo (ed.). Ciudades y villas camineras jacobeas: III Jornadas de Estudio y Debate Urbanos. León: Universidad de León, 225-245.

Lois González, Rubén C. y Santos Solla, Xosé M. (1999). «El Camino de Santiago». AECIT, La actividad turistica española en 1998. Madrid: AECIT y Universidad de Almería, 597-605.

Lois González, Rubén C. y Somoza Medina, José Antonio (2003). «Cultural tourism and urban management in northwestern Spain: The pilgrimage to Santiago de Compostela». Tourism Geographies, 5 (4), 446-461.

López, Lucrezia (2011). La imagen de Santiago de Compostela y del Camino en Italia: Su creación y divulgación con el paso del tiempo. Santiago de Compostela: Universidade de Santiago de Compostela. Tesis doctoral (en preparación).

Mazumdar, Shampa y Mazumdar, Sanjoy (2004). «Religion and place attachment: A study of sacred places». Journal of Environmental Psychology, 24, 385-397.

Morinis, Alan (ed.) (1992). Sacred Journeys: The Anthropology of Pilgrimage. Wesport, Connecticut: Greenwood Press.

Nolan, Mary Lee y Nolan, Sidney (1989). Christian Pilgrimage in Modern Western Europe. Chapel Hill, North Carolina: University of North Carolina Press.

Oursel, Raymond (1978). Pèlerins du Moyen Age: les hommes, les chemins, les sanctuaires. París: Fayard.

Plötz, Robert (1995). «La peregrinación como principio spiritual-religioso en un mundo real-concreto". En: Actas del Congreso de Estudios Jacobeos. Santiago de Compostela, 4 al 6 de noviembre de 1993. Santiago de Compostela: Dirección Xeral de Promoción do Camiño de Santiago, 611-628.

Possamai, Adam (2003). «Alternative Spiritualities and the Cultural Logic of Late Capitalism». Culture and Religion, 4 (1), 31-45.

Prorok, Carolyn (1997). «Becoming a Place of Pilgrimage: An Eliadean Interpretation of the Miracle at Ambridge, Pennsylvania». En: STODDARd, Robert H. y Morinis, Alan (eds.). Sacred Places, Sacred Spaces: The Geography of Pilgrimage. Baton Rouge: Louisiana State University / Geoscience Publications, 117-139.

Raffestin, Claude (1980). Pour une géographie du pouvoir. París: Litec.

Richman, Michèle (2002). Sacred revolutions: Durkheim and the College de Sociologie. Minneapolis, MN: University of Minnesota Press.

Rinschede, Gisbert (1992). "Forms of Religious Tourism». En: Annals of Tourism Research, 19 (1), 51-67.

- (1997). "Pilgrimage Studies at different Levels». En: Stoddard, Robert H. y Morinis, Alan (eds.). Sacred Places, Sacred Spaces: The Geography of Pilgrimage. Baton Rouge: Louisiana State University / Geoscience Publications, 95-115.

Rigobello, Armando (2003). «La struttura dell'interiorità e la pratica del cammino». En: Agís Villaverde, Marcelino y Vicente Ríos, Jesús (eds.). Filosofía del camino 
y camino de la Filosofía. Santiago de Compostela: Servicio de Publicaciones de la Universidad de Santiago de Compostela, 193-201.

Roger, Alain (2007). Breve tratado del paisaje. Madrid: Biblioteca Nueva.

Santomil Mosquera, David (2011). A imaxe exteror de Galiza durante o século XXI. Universidade de Santiago de Compostela. Departamento de Xeografía. Tesis doctoral.

Smith, Valene L. (1992). «Introduction. The quest in guest». Annals of Tourism Research, 19 (1), 1-17.

Stoddard, Robert y Morinis, Alan (eds.) (1997). Sacred Places, Sacred Spaces: The Geography of Pilgrimage. Baton Rouge: Louisiana State University / Geoscience Publications.

Stopani, Renato (2001). Il «Camino» Italiano per Santiago de Compostela. Florencia: Le Lettere.

Turner, Victor (1969). The Ritual Process: Structure and Anti-Structure. Ithaca, NY: Cornell University Press.

- (1974). Dramas, Fields and Metaphors: Symbolic Action in Human Society. Ithaca, NY: Cornell University Press.

Turner, Victor y Turner, Edith (1978). Image and Pilgrimage in Christian Culture. Nueva York: Colombia University Press.

Turnbull, Colin (1992). «Postscript: Anthropology as Pilgrimage, Anthopologist as Pilgrim». En: Morinis, Alan (eds.). Sacred Journeys: The Anthropology of Pilgrimage. Connecticut: Greenwood Press, 257-274.

Wagner, Philip L. (1997). "Pilgrimage: Culture and Geography». En: Stoddard, Robert H. y Morinis, Alan (eds.). Sacred Places, Sacred Spaces: The Geography of Pilgrimage. Baton Rouge: Louisiana State University / Geoscience Publications, 299-323.

Vázquez de Parga, Luis; Lacarra, José Ma . y Uría Ríu, Juan (1948). Las peregrinaciones a Santiago de Compostela. 3 tomos. Madrid: Consejo Superior de Investigaciones Científicas.

Xunta de Galicia (1992). Liber Sancti Jacobi «Codex Calixtinus». Ed. X. Carro Otero. Traducción de A. Moralejo, C. Torres y J. Feo. Santiago de Compostela: Xunta de Galicia, Xacobeo 93. 